\title{
The Use of Airflow Tests and Anthropological Measurements in Assessing the Voice Range of Professional Singers
}

\author{
Dins Sumerags, Mara Pilmane, Gunta Sumeraga \\ Riga Stradinš University
}

\section{INTRODUCTION}

In the vocal arts, it is difficult to determine the exact type of human voice, and it is particularly challenging to identify the voice category of vocalist-beginners because the diapason of the voice has not fully developed. A vocalist often develops his or her voice in an unsuitable tessitura (sings in a wrong voice type) resulting in a loss of sound quality and damage to the voice. An objective metric-based system for the determination of the human voice is needed.

The detection for the correlation between the airflow and vital capacity of the lungs, anthropometric data of the singers and the type of the human voice.

\section{MATERIALS AND METHODS}

Sixty vocalists (ten sopranos, ten mezzo-sopranos, ten altos, ten tenors, ten baritones, and ten basses) were examined during this experimental research. All participants were professional singers who have been very successful singing in their voice category for more than five years. The Jaeger spirograph was used to investigate the volume of the peak expiratory flow of representatives of various voice categories, i.e. by measuring the speed of airflow in a time unit (per second). Measurements were made of height, body weight, vital lung capacity, and volume of the air flow per second in the big, middle and small bronchial tubes.

To analyse the results, leading indicators of descriptive statistics were calculated, and one-factor disperses analysis (ANOVA) was used in equivalence testing calculations of the average values of morphological qualities. All statistical calculations were performed with the "Statistics" programme (7.0 edition).

\section{RESULTS}

The average height of the vocalists: sopranos - 165,8; mezzo-sopranos - 168,1; altos - 175,8; tenors - 180,5; baritones - 187,5; basses - 188,2.

The average weight of the singers $(\mathrm{kg})$ : sopranos - 60,2; mezzo-sopranos - 70,5; altos - 74,1; tenors - 87,7; baritones - 91,4; basses - 92,6.

The average vital lung capacity of the singers (L): sopranos - 3,79; mezzo-sopranos - 3,96; altos - 4,35; tenors 5,13; baritones - 6,06; basses - 6,12.

The average peak expiratory flow of the singers per second $(\mathrm{L} / \mathrm{s})$ : sopranos - 7,44; mezzo-sopranos - 7,43; altos - 8,19; tenors - 9,80; baritones - 11,49; basses - 11,2.

The average volume of the air flow per second in the big bronchial tubes of the singers $(\mathrm{L} / \mathrm{s})$ : sopranos - 6,49; mezzosopranos - 9,29; altos - 7,42; tenors - 7,91; baritones - 10,07; basses - 9,77.

The average volume of the air flow per second in the middle bronchial tubes of the singers (L/s): sopranos - 4,60; mezzosopranos - 4,02; altos - 4,96; tenors 4,46; baritones - 5,79; basses - 5,73.

The average volume of the air flow per second in the small bronchial tubes of the singers (L/s): sopranos - 1,98; mezzosoprano - 1,49; altos - 1,99; tenors - 1,69; baritones - 2,24; basses - 2,17.

There was a correlation between the airflow results e.a. Vital capacity, MEF 75 MEF 50 and PEF and the type of human voice, but there was no correlation between PEF 25 and the type of human voice.

There was a positive correlation between anthropometric data like weight and height and the pitch of the voice.

\section{CONCLUSION}

There is a correlation between the type of human voice and a person's height, weight as well as their vital lung capacity and peak expiratory flow. According to our research data, an algorithm could be made for the determination of the type of human voice to avoid voice damage and health problems related to the forced use of the voice in a wrong pitch.

\section{KEYWORDS}

Voice type, airflow test, anthropological measurements 